\title{
CORRIGENDUM: Dysregulation of bacterial proteolytic machinery by a new
} class of antibiotics

H Brötz-Oesterhelt, D Beyer, H-P Kroll, R Endermann, C Ladel, W Schroeder, B Hinzen, S Raddatz, H Paulsen, K Henninger, J E Bandow, H-G Sahl \& H Labischinski

Nat. Med. 11, 1082-1087 (2005)

In the introduction of the article, the producer strain of the 'A54556 complex' was incorrectly referred to as “Streptococcus hawaiiensis NRRL 15010."

The correct sentence should be: "A group of eight closely related acyldepsipeptides (ADEPs) was previously isolated from the fermentation broth of Streptomyces hawaiiensis NRRL 15010 and briefly described as the 'A54556 complex' in a patent."

CORRIGENDUM: Disabling poxvirus pathogenesis by inhibition of Abl-family tyrosine kinases

P M Reeves, B Bommarius, S Lebeis, S McNulty, J Christensen, A Swimm, A Chahroudi, R Chavan, M B Feinberg, D Veach, W Bornmann, M Sherman \& D Kalman

Nat. Med. 11, 731-739 (2005)

During final preparation of the figures, the authors inadvertently reproduced Figure $\mathbf{5 b}$ as Figure $\mathbf{5 a}$. The correct versions of Figure $\mathbf{5} \mathbf{a}$ and Figure 5b are shown below.

No virus

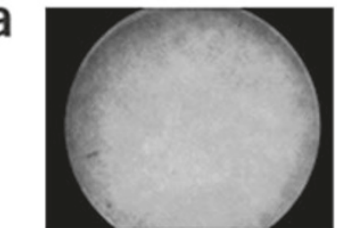

b

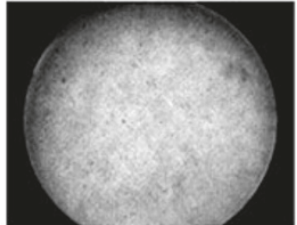

Neat
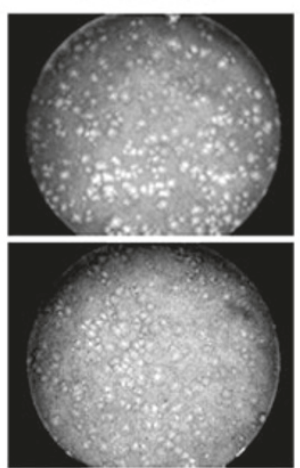

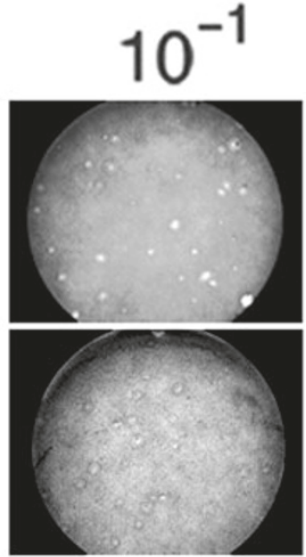

$\mathrm{SrC}^{-1-} \mathrm{Fyn}^{-1-}$

Yes1-l- SN 